\title{
Investigation of Structure and Properties of High-strength Bimetallic Materials Produced By Explosion Welding and Have Been Exploited in Arctic Climate
}

\author{
E.A. Putilova1, S.M. Zadvorkin¹, E.S. Gorkunov¹, and A.V. Makarov¹,2,3 \\ ${ }^{1}$ Institute of Engineering Science UB RAS, Ekaterinburg, Russia \\ ${ }^{2}$ Mikheev institute of Metal Physics UB RAS, Ekaterinburg, Russia \\ ${ }^{3}$ Ural Federal University, Ekaterinburg, Russia
}

\section{Abstract}

The paper presents the results of a comparative study of the structure, mechanical and magnetic properties of bimetallic materials obtained by explosion welding technology. The main layer of the studied bimetals is made of high-strength hull steel, and cladding - was performed by two corrosion-resistant steels with different degrees of austenite

Corresponding Author:

E.A. Putilova

tuevaevgenya@mail.ru

Received: 25 February 2019

Accepted: 9 April 2019

Published: 15 April 2019

Publishing services provided by Knowledge E

(c) E.A. Putilova et al. This article is distributed under the terms of the Creative Commons

Attribution License, which permits unrestricted use and redistribution provided that the original author and source are credited.

Selection and Peer-review under the responsibility of The Ural school-seminar of metal scientists-young researchers Conference Committee. stability. According to the results of the shear test, it has been shown that explosion welding provides a solid one-piece connection with high values of the bond strength of the layers. Installed informative magnetic parameters could be used to develop non-destructive methods for assessing the changes occurring in the structure and phase composition of one of the bimetal layers under the action of plastic deformation.

Keywords: Magnetic non-destructive testing methods, high-strength bimetal materials, corrosion resistance, differential magnetic permeability, structure, cold rolling, explosion welding.

\section{Introduction}

Double-layer materials clad with corrosion-resistant steels are increasingly being used as materials for hull structures operating in aggressive environments. Two-layer materials began to be used as hull material in the second half of the 20th century [1] to ensure high corrosion and erosion resistance of atomic icebreakers. Currently, the development of the Arctic regions, the implementation of large-scale projects in northern latitudes, the use of the northern sea route lead to the necessity the use of more powerful icebreakers, which leads to greater ice loads and, as a consequence, the need to use advanced corrosion-resistant materials, which also have high strength characteristics [1-4].

To ensure safety operation of products made of laminated materials, as well as to assess the residual life of parts and structural elements, it is necessary to diagnose 
changes that occur during operation both in the layered material as a whole and in its components. At present, there are no adequate methods for non-destructive testing of the current state of individual layers in bimetallic materials under the conditions of current stresses.

In this work, we investigated the structure, phase composition, mechanical and magnetic properties of structural steel, clad with corrosion-resistant steels with varying degrees of austenite stability in order to determine the possibility of using magnetic methods to diagnose the current state of such materials.

\section{Results and Disscustion}

Two two-layered materials were obtained: "constructional steel - high-nitrogen containing steel" and "constructional steel - AISI 304". The chemical composition of investigated materials is presented in Table 1. After explosion welding, the samples were subjected to cold pack rolling with varying degrees of rolling in order to investigate the possibility of using magnetic diagnostic methods to assess the changes occurring during plastic deformation in the structure, phase composition, and physical-mechanical properties of the two-layered materials under the study. Also for the completeness, individual components of the layered materials were subjected to the same processing methods.

TABLE 1: Chemical composition of investigated steels, Wt.\%.

\begin{tabular}{|c|c|c|c|c|c|c|c|c|c|c|c|c|}
\hline Materials & C & $\mathrm{Si}$ & $\mathrm{Mn}$ & $P$ & $S$ & $\mathrm{Cr}$ & $\mathrm{Ni}$ & Mo & $\mathrm{Cu}$ & $\mathrm{Ti}$ & $\mathrm{Nb}+\mathrm{V}$ & $\mathrm{N}$ \\
\hline $\begin{array}{l}\text { High-nitrogen } \\
\text { containing steel }\end{array}$ & 0.07 & 0.22 & 10.97 & 0.02 & 0.01 & 18.64 & 6.74 & 1.74 & 0.07 & 0.01 & 0.35 & 0.54 \\
\hline AISI 304 & 0.06 & 0.58 & 0.98 & 0.04 & 0.01 & 19.04 & 7.84 & 0.08 & 0.05 & 0.01 & 0.18 & - \\
\hline $\begin{array}{l}\text { Constructional } \\
\text { hull steel }\end{array}$ & 0.11 & 0.24 & 0.40 & 0.01 & 0.003 & 0.68 & 4.18 & 0.46 & 1.28 & - & 0.16 & - \\
\hline
\end{tabular}

To assess the strength joint of the connection of the layers, shear tests were carried out. The appearance of the samples is shown in Fig. 1. According to the test results, it was found that the shear resistance of both materials is $560 \mathrm{MPa}$.

Microstructural investigations devoted to the study of the boundary between the layers during explosion welding, show that increasing the degree of cold rolling of layered materials leads to a decrease in the wave-like boundary obtained during explosion welding [5-8]. It was also found that, with an increase in the degree of cold rolling, grain refinement occurs in all deformable materials. 

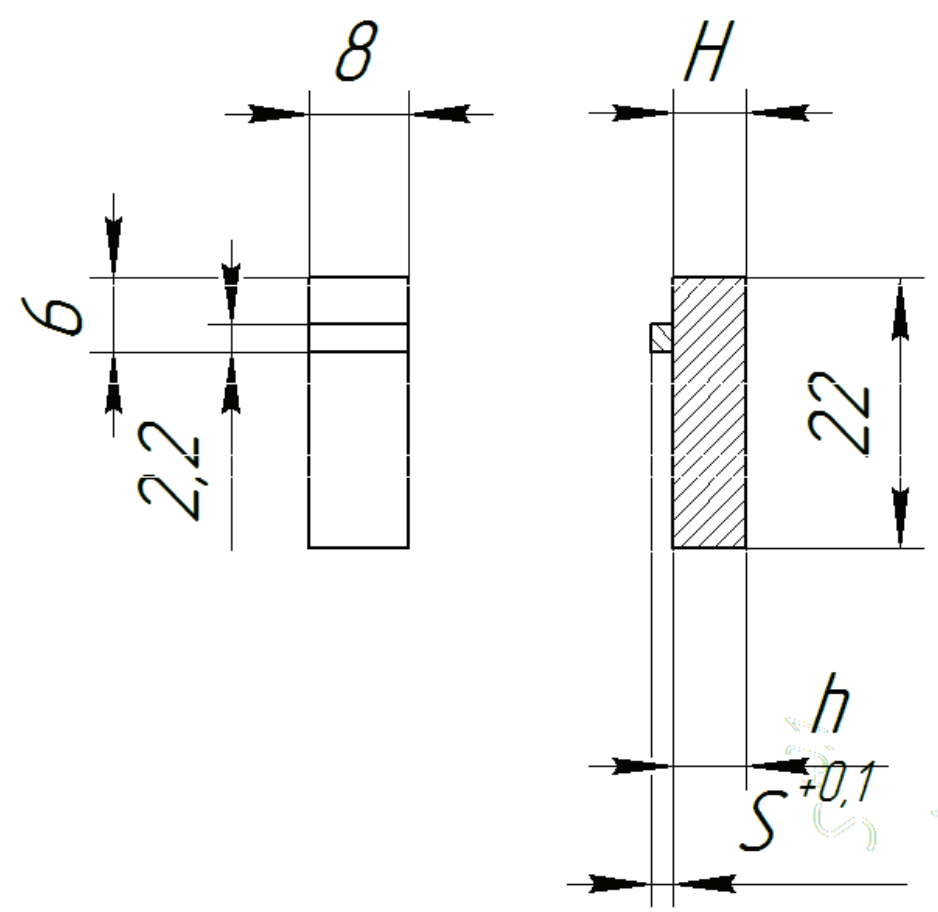

Figure 1: Sample drawing for shear tests.

Metallographic and X-ray phase analyzes (Fig.2) carried out on all the studied samples confirmed the purely austenitic structure in both corrosion-resistant steels in the initial state, also after deformation by cold rolling in the high-nitrogen containing steel, which indicates the stability of the structural state of this steel during plastic deformation. From fig.2a it is also clearly seen that the structure of AISI 304 steel is approximately equiaxial austenite grains of $25-40$ microns in size. The structure is also characterized by the presence of twins.

According to optical microscopy data, the structure of high-nitrogen containing steel consists of anisomerous austenite grains of $10-40 \mu \mathrm{m}$ in size with twins. Investigations of the fine structure of highOnitrogen containing steel at the initial state by electron transmission microscopy revealed a heterogeneous structure (Fig. 3.) of this steel, which is characteristic of the state formed during hot rolling [9]. There are areas with a band structure consisting of austenite subgrains with predominantly in one direction with different, including low, dislocation density (Fig. 3a). The austenitic structure also contains numerous particles with different sizes and shapes (Fig. 3a - c). From small (up to 50-100 $\mathrm{nm}$ in size) particles of nitrides $\mathrm{V}, \mathrm{Cr}, \mathrm{Nb}$, fixing dislocations, on diffraction patterns one can see blurred reflexes - arms (see. Fig. 3c). There are also large individual particles with a size of $500-700 \mu \mathrm{m}$, for example, in Fig. $3 \mathrm{~d}$ presents a similar particle with a facet 

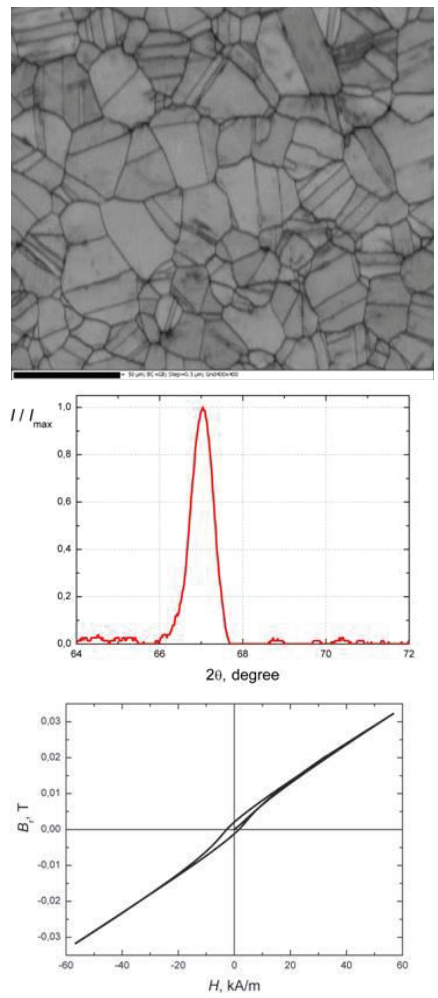

a)
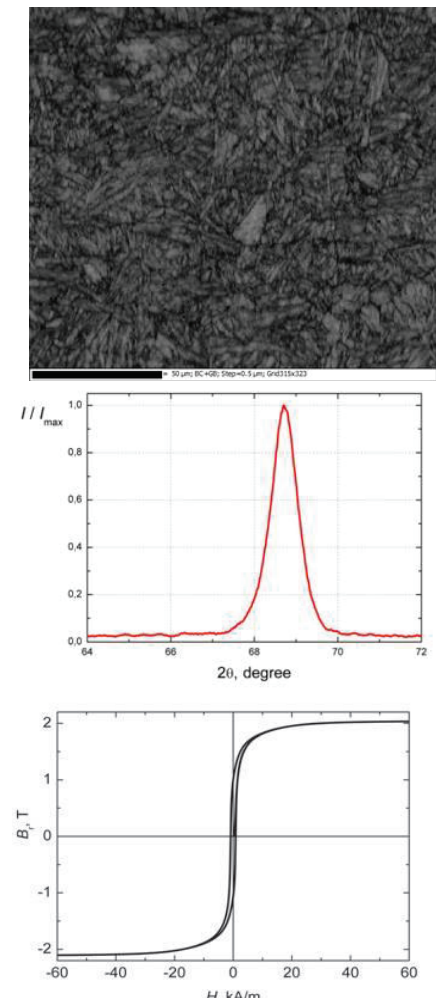

b)
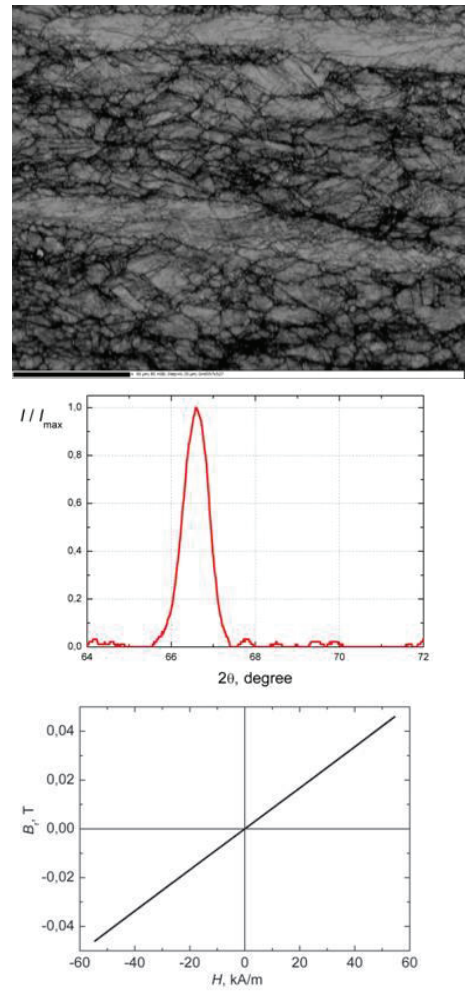

c)

Figure 2: The results of Metallographic, X-ray phase and magnetic analyzes of investigated materials at the initial state.

and an interplanar distance of $2.52 \AA$, which corresponds to the niobium nitride (or a complex nitride with a predominance of niobium).

During cold rolling in AISI 304 steel have undergone the phase transformation and the martensite deformation occurs, which is an undesirable ferromagnetic phase and leads to a decrease in resistance to intergranular corrosion. Moreover, with an increase in the degree of deformation by cold rolling, its amount, both in a separate component and in the composition of a bimetal, increased (Fig. 4).

Figure $4 \mathrm{~b}$ shows the field dependence of the differential magnetic permeability for metastable AISI 304 steel. It is clearly seen that with increasing degree of deformation by rolling, the height of the peak increases, the field of localization of the peak, as is known [], approximately coincides with the values of the coercive force of the material. The increase in the peak height is due to the formation of a new ferromagnetic phase, $\alpha /$ martensite deformation. Also, the diagnosis of the formation of a magnetically ordered phase in these steels could be performed by measuring the maximum magnetization in the maximum applied field (saturation magnetization), the maximum magnetic permeability and the root-mean-square values of the Barkhausen magnetic noise voltage, which vary monotonically with the degree of the deformation. 


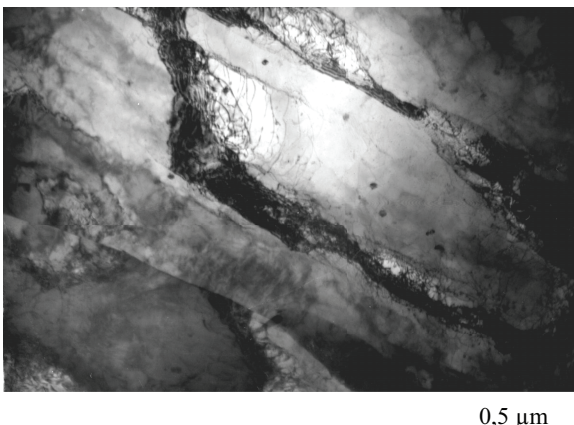

(a)

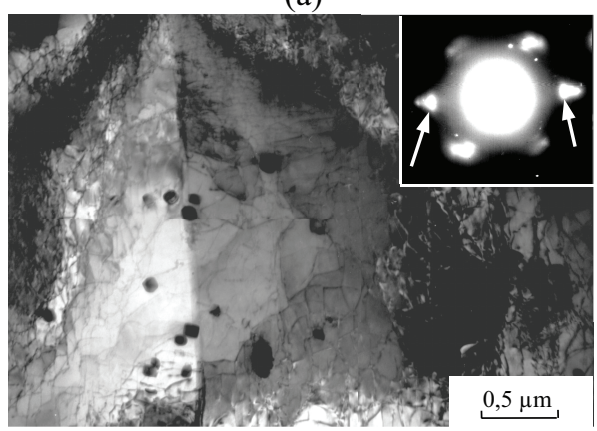

(c)

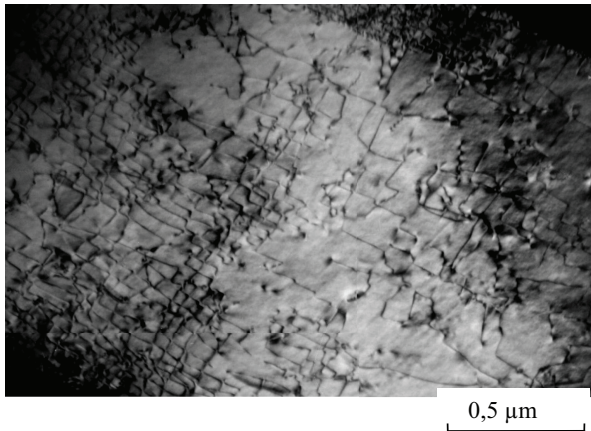

(b)

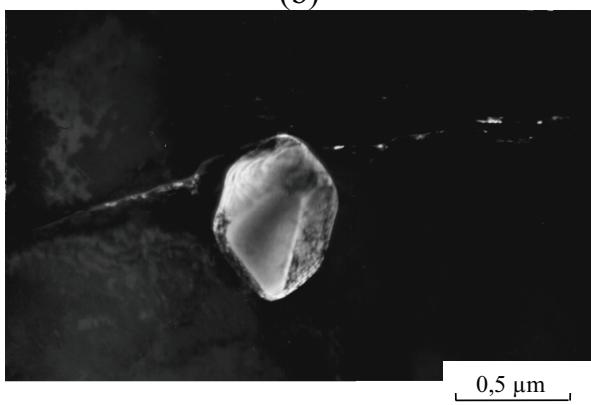

(d)

Figure 3: Electron-microscopic image of the structure of high-nitrogen containing steel: $\mathrm{a}-\mathrm{c}-$ bright-field images; (d) dark-field image in the (111) $\mathrm{NbN}$ reflex. On microdiffraction pic. 3c, arrows indicate the bows reflexes from dispersed (111) nitrides $(\mathrm{V}, \mathrm{Cr}) \mathrm{N}$.

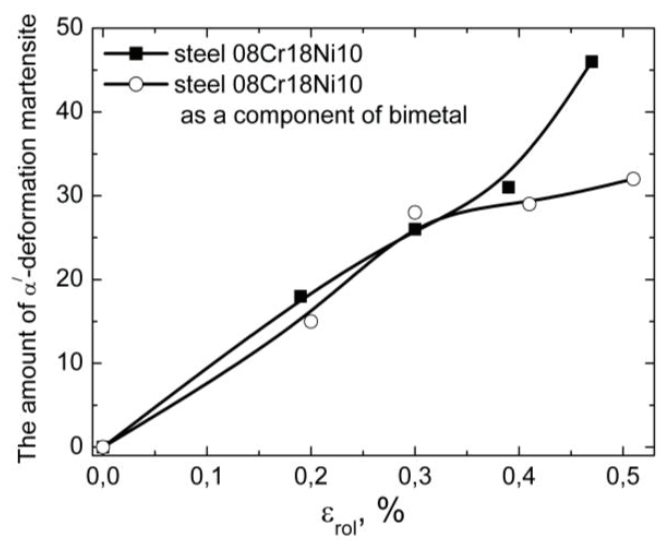

a)

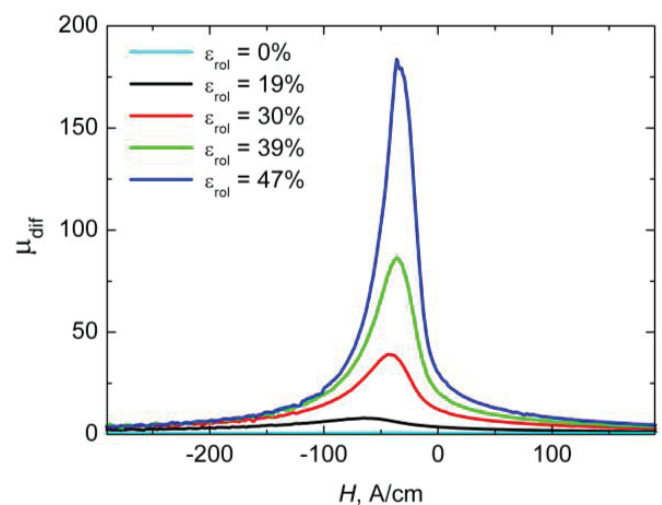

b)

Figure 4: The amount of deformed martensite (a) and the field dependences of the differential magnetic permeability (b) for cold-rolled with different deformation degree by rolling AISI 304 steel.

In fig. 5 it is shows the field dependences of the differential magnetic permeability of the bimetal "constructional steel - AISI 304" with an increase in the degree of deformation by rolling. On these curves with a deformation of more than 0.30 , it could be clearly seen that two peaks form on these dependences: the first - in weaker fields, but higher in intensity - characterizes the ferromagnetic phase (ferrite) in the component of constructional hull steel. The second peak, which is localized in stronger fields and belongs to the newly formed as a result of rolling phase - martensite deformation in a 
component of AISI 304 steel. Thus, with the help of magnetic methods, it is possible to diagnose changes occurring in layered materials, and in its individual components.

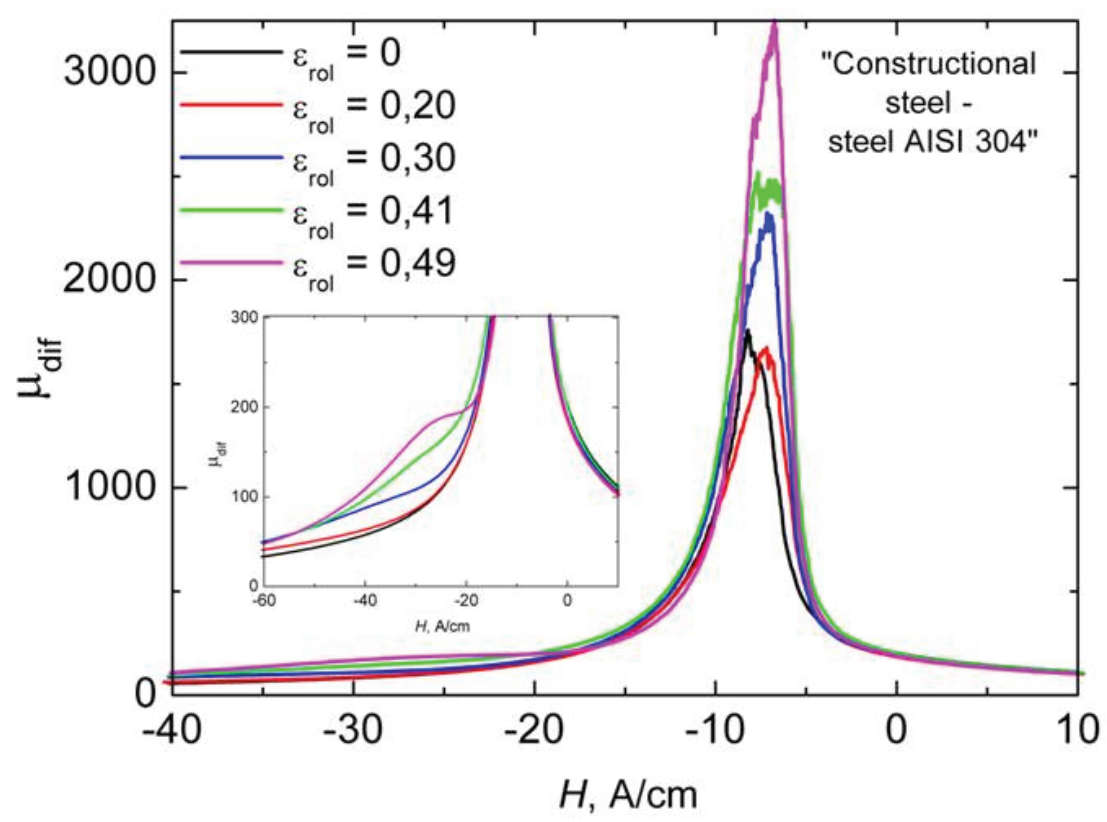

Figure 5: Field dependences of the differential magnetic permeability for the bimetal "Constructional steel - steel AISI 304" at various degrees of deformation by cold rolling.

\section{Conclusion}

The values of the maxima in the field dependences of the differential magnetic permeability of layered materials could serve as parameters for diagnosing the formation of a new magnetically ordered phase and its quantity formed during plastic and elastoplastic deformation. The field values at which maxima are formed in the dependences of the differential magnetic permeability of layered materials and their individual components could be used to estimate the degree of deformation by rolling and uniaxial stretching of these materials.

The results obtained are important and relevant for the subsequent work on the development of methods for non-destructive evaluation of changes occurring in layered high-strength materials during the operation cycle. 


\section{Acknowledgements}

The work was partially supported by the RFBR, grant No 16-38-60027. The researchers used the equipment the "Plastometriya" collective use center.

\section{References}

[1] G.Yu. Kalinin, S.Yu. Mushnikova, O.V. Fomina, O.A. Kharkov, Two-layered clad steel with high corrosion-erosion resistanse, Chemical-metallurgical processes and materials of metallurgical productions, 1 (2016) 231-232.

[2] A.S. Oryshchenko, V.A. Malyshevsky, E.I. Khlusova, Modern constructional steel for application in Arctic region, Sudostroenie 3 (2013) 46-49.

[3] E.I. Khlusova, V.V. Orlov, The structural and properties changes in heat affected zone of the weld joints of low-carbon shipbuilding and pipe steels, Metallurg 9 (2012) 6376.

[4] E.A. Chernyshev, A.D. Romanov, E.A. Romanova, High-strength shipbuilding steels and alloys, Metallurg 2 (2016) 59-63.

[5] R. Mendes, J.B. Ribeiro, A. Loureiro, Effect of explosive characteristics on the explosive welding of stainless steel to carbon steel in cylindrical configuration, Materials and Design 51 (2013) 182-192.

[6] E. Zamani, G.H. Liaghat, Explosive welding of stainless steel-carbon steel coaxial pipes, Journal of materials science 47 (2012) 685-695.

[7] Y. Kaya, K. Nizamettin, An investigation into the explosive welding/cladding of Grade A ship steel/AISI 316L austenitic stainless steel, Materials \& Design 52 (2013) 367-372.

[8] S.V. Gladkovskii, T.A. Trunina, E.A. Kokovikhin, D.I. Vichuzhanin, I.A. Golubkova, Structure and properties of explosion-welded composite from steels $12 \mathrm{kh} 18 \mathrm{n} 10 \mathrm{t}$ and 20, Metal Science and Heat Treatment 9-10 (51) (2009) 444-449. 
[9] E.S. Gorkunov, E.A. Putilova, S.M. Zadvorkin, A.V. Makarov, N.L. Pecherkina, G.Y. Kalinin, S.Y. Mushnikova, O.V. Fomina, Behavior of magnetic characteristics in promising nitrogen-containing steels upon elastoplastic deformation, The Physics of Metals and Metallography 8 (2015) 838-849.

[10] M.N. Mikheev, E.S. Gorkunov, Magnetic methods for structural analysis and nondestructive testing, Moscow: Nauka, 1993. 